\title{
Evaluation of a Policy, Systems, and Environmental-Focused Faith-Based Health Promotion Program
}

\author{
Annie Hardison-Moody, $\mathrm{PhD}^{1}$; Serena Fuller, PhD, $\mathrm{RDN}^{2}$; Lorelei Jones, $\mathrm{MEd}^{1}$; \\ Karen Franck, $\mathrm{PhD}^{3}$; Rosemary Rodibaugh, PhD, RD, LD*; Lisa Washburn, DrPH ${ }^{3}$; \\ Lacey Corrick, MS, RD, LD/N ${ }^{4}$; Karla Pagan Shelnutt, PhD, RD ${ }^{4}$; Lareissa Stumm, MSPH ${ }^{1}$; \\ Alice S. Ammerman, DrPH ${ }^{5}$
}

\begin{abstract}
Objective: This study assessed the impact and lessons learned from implementing policy, systems, and environmental (PSE) changes through Faithful Families Thriving Communities (Faithful Families), a faith-based health promotion program, in 3 southern states.

Methods: Faithful Families classes and PSE changes were implemented through a coordinated effort between the Expanded Food and Nutrition Education Program (EFNEP) and Supplemental Nutrition Assistance Program-Education (SNAP-Ed). Changes were measured using a faith community assessment, site reports, and annual reporting.

Results: Thirteen faith communities participated in the intervention. A total of 34 PSE changes were implemented across the 3 states, affecting 11 faith communities with 4,810 members across sites.

Conclusions and Implications: Programs such as Faithful Families can allow EFNEP and SNAP-Ed to coordinate to implement PSE changes in community settings. However, these types of coordinated programs to support faith communities require time for relationship building and trust, adequate training, and strong support for faith-based lay leaders as they carry out this work.

Key Words: faith-based, nutrition, Expanded Food and Nutrition Education Program, Supplemental Nutrition Assistance Program-Education, physical activity (J Nutr Educ Behav. 2020; 52:640-645.)
\end{abstract}

Accepted November 18, 2019. Published online January 8, 2020.

\section{INTRODUCTION}

Low-income communities and communities of color experience higher rates of diet-related diseases such as diabetes, heart disease, and some cancers. ${ }^{1,2}$ To address these health disparities, federally funded nutrition education programs such as the Expanded Food and Nutrition Education Program (EFNEP) and Supplemental Nutrition Assistance Program-Education

\footnotetext{
${ }^{1}$ Department of Agricultural and Human Sciences, North Carolina State University, Raleigh, NC ${ }^{2}$ Department of Health and Human Services, Cosumnes River College, Sacramento County, CA

${ }^{3}$ Department of Family and Consumer Sciences, University of Tennessee, Knoxville, TN

${ }^{4}$ Department of Family, Youth, and Community Sciences, University of Florida, Gainesville, FL

${ }^{5}$ Department of Nutrition, Gillings School of Global Public Health, University of North Carolina at Chapel Hill, Chapel Hill, NC

${ }^{\star}$ Retired

Conflict of Interest Disclosure: The authors have not stated any conflicts of interest.

Address correspondence to: Annie Hardison-Moody, PhD, Department of Agricultural and Human Sciences, North Carolina State University, 512 Brickhaven Dr, Campus Box 7606, Raleigh, NC 27695-7606; E-mail: amhardis@ncsu.edu
}

(SNAP-Ed) historically provided handscommunities across the US. These grams have had sustained success in health behaviors such as sumption, planning and eating more meals at home, and increasing physiAlthough these nutrition education programs demonstrated success in improving health outcomes and

https://doi.org/10.1016/j.jneb.2019.11.011 behaviors, public health research and practice increasingly shifted to include a more ecological approach to health promotion, emphasizing that an individuals' behavior is affected by the social, cultural, neighborhood, and political environments in which they reside. ${ }^{5}$ Approaches based on the socioecological model acknowledge that differences in behavioral outcomes across markers of race, ethnicity, gender, and income are likely attributable to broader social and structural forces that affect health.

As public health research and practice shifted to include ecological approaches, EFNEP and SNAP-Ed national guidance likewise recognized a need to blend traditional nutrition education efforts with sustained work to improve policies, systems, and environments (PSE) in which people live, learn, work, play, and worship. The Community Nutrition Education Logic Model, for example, encourages programs to address healthy eating and physical activity at 3 levels: "individual, family, or household level; institution, organization, or community level; and social 
structure/policy level." ${ }^{6}$ Both EFNEP and SNAP-Ed guidance emphasize that in addition to individual-level nutrition education, programs should work with partners to address broader PSE changes that can have an impact on health behaviors in low-income communities. Because of these programmatic parameters, serving low-income audiences effectively will require increased collaboration between these 2 federally funded programs to ensure that families living in poverty have access to tools, resources, and support to improve long-term behaviors and equitable access to healthy foods and places to be active that will better position them to make those changes.

Research demonstrated that faith communities can be powerful partners in local efforts to improve individual and community health, particularly for low-income communities and communities of color. ${ }^{7,8}$ For example, faith-based interventions effectively improved nutrition and physical activity behaviors, increased the amount of healthy foods served in faith community settings, and helped participants make meaningful connections between their religious practices and beliefs and their health to encourage sustained behavior changes. ${ }^{9-12}$ Other faith-based interventions, working across multiple levels of the socioecological model, encouraged healthy behaviors by implementing PSE changes to support health and adopted broader community-level strategies to affect health outcomes and address health equity. 9,10,13 This type of multilevel, community-based approach was effective in helping faith community members advocate for policy and environmental changes that promote healthy eating and physical activity in their organization and the community at large. $^{13}$

The primary aim of this study was to examine the impacts of Faithful Families program delivery on adoption of PSE changes to support healthy eating and physical activity in faith communities across 3 states that participated in the US Department of Agriculture-funded Regional Center for Nutrition Education and Obesity Prevention, Southern Region (RNECESouth). A secondary aim was to determine whether and how this program provided opportunities for partnership between EFNEP and SNAP-Ed, particularly as they relate to combining direct education with PSE changes.

\section{METHODS}

\section{Project Overview}

In 2014, the US Department of Agriculture established the RNECE to demonstrate the effectiveness of SNAP-Ed and EFNEP and to identify changes to improve both programs. The RNECE centers were designed to supplement and enhance ongoing program monitoring efforts and evaluation activities to strengthen the evidence-base of SNAP-Ed and EFNEP by ensuring their effectiveness, innovation, replicability, sustainability, and cost-effectiveness. Five regional centers and a coordinating center were funded; this project served as a core research effort of the Southern Regional Center, which was a collaboration between researchers and practitioners at the University of North Carolina at Chapel Hill and North Carolina State University, guided by a steering committee of representatives from each southern state.

The RNECE-South center funded 3 universities (University of Arkansas, University of Tennessee, and University of Florida) to implement Faithful Families through their EFNEP and SNAP-Ed programs. The goal was for EFNEP and SNAP-Ed to collaborate in program implementation to affect healthy eating and physical activity across the socioecological model. Each state developed an implementation plan that matched their unique locations and needs. In Tennessee, 2 counties were selected for this project: 1 was implemented by an EFNEP paraprofessional in an urban setting and 1 by a SNAP-Ed paraprofessional in a rural setting. The paraprofessionals each recruited 1 church, for a total of 2 churches. In Arkansas, 5 counties and 6 faith communities were selected. Of the 5 areas, 3 counties and 3 sites were led by SNAP-Ed professionals and 2 counties with 3 sites were led by EFNEP paraprofessionals with assistance from SNAP-Ed professional staff. In Florida, 2 counties were selected for this project, with 4 sites in an urban setting and 1 in a rural setting. In all 5 sites, an EFNEP paraprofessional led programming with assistance from a SNAP-Ed professional staff.

To support state-level programmatic implementation, members of the Faithful Families Development Team (North Carolina State University) traveled to each university to train university staff and local program facilitators on program implementation. They also were available for technical assistance and support, both informally and through regularly scheduled calls. Faithful Families team members conducted site visits in each state at the close of the project, meeting with facilitators, lay leaders (trained volunteers from the faith community sites), community partners, and clergy who participated in the project to learn about barriers and successes in program implementation.

\section{Faithful Families}

Faithful Families is a faith-based intervention developed by North Carolina State Extension and the North Carolina Division of Public Health that promotes healthy eating and physical activity across multiple levels of the socioecological model. ${ }^{10}$ Trained extension staff and faith-based lay leaders codeliver a 9-lesson series of classes to program participants. Aspects of each lesson focus on how individuals, families, and faith communities make changes to affect their environments to promote healthy foods and physical activity. Lay leaders are nonclergy members of a faith community who provided leadership for faith community programming. Lay leaders co-teach lessons, bringing religious elements to each lesson and drawing on prompts in the 9-lesson curriculum to help participants make connections between their faith and their health. Lay leaders also partner closely with facilitators to implement PSE changes in each faith community, drawing on a faith community assessment (FCA) and dialogue that occurs during the 9-lesson series to select strategies. Then, program staff supports faith communities with technical assistance and/or materials as they implement PSE changes. 


\section{Participant Recruitment and} Outcomes

The program was open to any religious organization that met SNAP-Ed requirements. Facilitators focused recruitment efforts in low-income areas by identifying faith communities located in census tracts where a majority of participants qualified for participation in the SNAP-Ed program. After qualifying faith communities were contacted and agreed to host a Faithful Families program, lay leaders and participants were recruited from within the faith community.

Data collection for the 3-state implementation was approved by the universities at each state participating in this project. In addition, North Carolina State University's institutional review board approved the analysis of deidentified data shared by each state as part of the broader Faithful Families national program implementation and evaluation.

\section{Policy, Systems, and}

\section{Environmental Changes}

Upon program enrollment, each faith community completed the Faithful Families FCA, an audit tool completed by a member of the faith community who could best answer the assessment questions (ie, faith leader/clergy member or lay leader) (Supplementary Data). ${ }^{10}$ This audit tool provides an initial assessment of the assets and needs of the faith community related to healthy eating and physical activity, in addition to basic demographic information about the faith community. The 91-question FCA was modeled on the Centers for Disease Control and Prevention Worksite Health ScoreCard $^{14}$ and was pilot-tested in 2015 with 10 faith communities across North Carolina; pilot testing resulted in minimal revisions. Overall, the FCA aims to identify gaps in programming and identify PSE supports and assets that can be harnessed for change. The results of the FCA along with PSE-specific discussion questions in each of the 9-lesson Faithful Families lessons guided the implementation of specific PSE changes implemented within each faith community. To facilitate these changes, SNAP-Ed educators at each site worked in partnership with lay leaders and members of the faith community.

\section{Policy, Systems, and Environmental Evaluation}

At the close of the program, each university submitted final progress reports, which included the number and type of PSE changes implemented in the faith communities where they worked, as well as descriptions of barriers and facilitators to program implementation (Table). In addition, 2 Faithful Families team members from North Carolina State University conducted site visits in each state to talk with facilitators, lay leaders, and participants about their experiences with the program. Extensive field notes were recorded at each site to identify and further clarify steps for EFNEP and SNAP-Ed PSE implementation in communities of faith.

\section{RESULTS}

Policy, Systems, and

Environmental Changes

In Tennessee, the 2 churches that completed the program implemented 8 PSE changes. These changes had the potential to affect 568 members across the 2 churches, as reported in the FCA. In Arkansas, 4 churches out of 6 sites implemented 12 PSE changes. These changes had the potential to affect 690 members (3 churches reported membership; 1 had missing data in the FCA). In Florida, at least 1 policy change and 1 environmental change were implemented at each of the 5 faith community sites, creating 14 PSE changes. These changes had the potential to affect the 3,552 members of these faith communities. A total of 34 PSE changes were implemented across the 3 states, affecting 11 faith communities, with the potential to affect 4,810 members of those faith communities (Table).

\section{Implementation Barriers}

Overall, recruiting faith communities took a lot of time and effort on the part of state and local extension staff. Arkansas was unable to implement the program with 2 faith communities per county as originally planned, because the recruitment process was so time-intensive. Florida staff found that in some interested faith communities, schedules were already full and the project's time line did not coincide with the availability of the faith community. For example, facilitators in Florida noted that if the faith community leader or pastor was out of town, many participants would not be present for events. Facilitators found that it was best to schedule events at a faith community when members had the least amount of conflicts. In addition, some faith communities had the requirement of a review committee to approve participation in research projects. This extended the recruitment process and might have deterred sites from participating. In addition, facilitators and staff noted that the Faithful Families program necessitated a significant time investment from church administrators, participants, and lay leaders, as confirmed by other faith-based health promotion studies. ${ }^{10,15,16}$

Other barriers included developing lay leaders from the faith community. This was a novel approach for state and local EFNEP and SNAPEd staff. Although local staff tried their best to outline all responsibilities of the lay leader position clearly, ultimately the selection of this volunteer position rested with the faith community, which meant that not all lay leaders were equally invested in program delivery. Staff implemented lay leader trainings and used materials from the curriculum to review roles and responsibilities during the training; however, some lay leaders found it difficult to commit to this volunteer role.

\section{Implementation Facilitators}

One facilitator to program success was strong collaboration at the state and local levels between EFNEP and SNAP-Ed staff, which enabled each program to draw on its strengths. For example, in several states, EFNEP paraprofessionals took the lead on direct education but partnered closely with SNAP-Ed professionals to lead PSE implementation. This partnership required strong coordination and a significant time investment at the regional, state, and local levels, particularly related to program 


\section{Faith Community}

Christian church 1-Florida

(3 PSE changes)

Mosque 1-Florida (2 PSE changes)

Christian church 2-Florida (4 PSE changes)

Christian church 3-Florida (2 PSE changes)

Christian church 4-Florida (3 PSE changes)

Christian church 1-Tennessee (4 PSE changes)

Christian church 2-Tennessee (4 PSE changes)

Christian church 1-Arkansas (3 PSE changes)

Christian church 2-Arkansas (3 PSE changes)

Christian church 3-Arkansas (3 PSE changes)

Christian church 4-Arkansas (3 PSE changes)

Total

\section{Type of PSE Change Implemented}

Physical activity environment: created walking trail Healthy eating environment: installed water dispenser Healthy eating environment: signage installed to encourage drinking water and walking

Health committee established

Healthy eating environment: created community garden

Physical activity environment: created walking trail

Physical activity policy: created policy to encourage walking meetings

Healthy eating environment: installed water dispenser

Healthy eating environment: signage installed to encourage drinking water and walking

Healthy eating environment: created community container garden

Healthy eating environment: installed water dispenser

Physical activity policy: created policy to encourage exercise on first and third weekly meeting each month

Physical activity environment: created exercise space onsite

Healthy eating environment: installed water dispenser

Healthy eating policy: water served at all events

Healthy eating policy: include grilled and baked foods at all events

Physical activity environment: created exercise space onsite

Physical activity environment: created walking trail

Healthy eating policy: water served at all events

Healthy eating policy: include sugar-free dessert options at all events

Physical activity environment: created exercise space onsite

Physical activity environment: created walking trail

Healthy eating policy: serve healthy options at all events

Healthy eating policy: water served at all events

Physical activity policy: created policy to encourage physical activity at meetings and events

Healthy eating policy: water served at all events

Healthy eating policy: serve healthy options at all events

Physical activity environment: created walking trail

Healthy eating policy: water served at all events

Healthy eating policy: serve healthy options at all events

Physical activity environment: created walking trail

Physical activity environment: created walking trail

Physical activity environment: created exercise space onsite

Healthy eating environment: created community garden 34 PSE changes
Total Faith Community Members, $\mathbf{n}$

35

400

100

Missing data

4,810

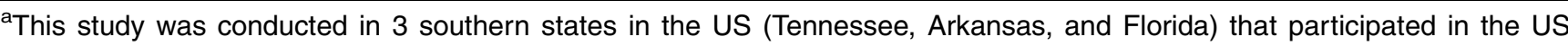
Department of Agriculture-funded Regional Center for Nutrition Education and Obesity Prevention, Southern Region to examine the impacts of Faithful Families program delivery on the adoption of PSE changes to support healthy eating and physical activity in faith communities.
}

evaluation and reporting. For example, extension staff received training to implement and track changes in PSEs in Tennessee and Florida, because EFNEP paraprofessionals' primary focus is on direct education.

Although recruiting lay leaders was challenging, facilitators found that lay leaders often enthusiastically owned recruitment responsibilities by communicating weekly with participants, providing transportation if 
necessary, and engaging participants in dialogue about PSE changes during class. In addition, implementing states noted that recruiting faith communities took a good deal of time; however, the faith communities that signed up for the program were invested and helped EFNEP and SNAP-Ed staff to recruit new audiences for their work. For example, a Family and Consumer Sciences (FCS) Agent in Tennessee shared during their site visit that she had worked in the county for 20 years but had never worked with the church that implemented the program. The conversations during the classes led church members to work with the FCS agent to reach out to the church across the street to expand the program and implement innovative practices such as hosting walking sermons, in which their respective pastors led groups of people on walks that incorporated spiritual lessons and teachings.

Finally, states reported that the implementation of PSE changes was successful because of its connection with the direct education through the 9-lesson class series, which incorporated education about the need for PSE changes.

\section{DISCUSSION}

The primary aim of this study was to evaluate Faithful Families program delivery, including the barriers and facilitators to PSE change implementation, in 3 states that participated in the RNECE-South signature project. Another aim was an assessment of how programs such as Faithful Families, which are based on the socioecological model, can help EFNEP and SNAP-Ed programs partner more effectively. The barriers and facilitators presented here offer some helpful insights for future programming to support PSE changes in faith-based health promotion.

First, it is important to recognize the time commitment that these interventions required, particularly because they aimed to empower and engage faith communities in becoming catalysts for health in their own congregation and the broader community. ${ }^{10,13,15}$ A growing body of research in religion and health affirms the importance of community-based participatory methods, recognizing and affirming the local wisdom of faith communities to develop programs and projects that are sustainable and adapted to the varied local realities that shape religious life and organizations. $^{11-13,17}$ Lay leader or lay health advisor models were also demonstrated to be effective methods for engaging faith communities in health promotion work. ${ }^{16,18,19}$ Faithful Families was developed to harness these community-based participatory approaches; it uses a dialogue-based curriculum and lay leader model to help faith communities identify assets and core values and make a plan to implement PSE changes that make sense for the community. This type of change work requires the engagement of a committed lay leader over months or even years, given the reality of busy faith community life and personal calendars. ${ }^{10}$ This project found that there were opportunities to improve the lay leader recruitment and training process as well as provide support for the lay leader model's efficacy in supporting PSE changes. Based on their experiences of recruiting lay leaders, paraprofessionals from Florida recommended training more than 1 lay leader per site. Although they did not implement this suggestion, these educators proposed offering an opportunity to change the lay leader's roles regularly, so that each person in the group could have a chance to lead, to help participants feel more engaged and invested in the program and build long-term support for sustainable PSE changes through a broader network of lay leaders in the community. To bolster implementation of this type of community intervention further, findings support allowing for adequate time to develop relations between staff and faith communities. Also, it would be helpful to provide more support for state and local staff specifically regarding how to work with lay leaders as co-teachers and on PSE approaches themselves.

In consideration of how EFNEP and SNAP-Ed might effectively partner to reach more individuals, each state has integrated Faithful Families or other faith-based initiatives into its EFNEP/ SNAP-Ed or FCS programming, or it plans to. This partnership approach supports EFNEP and SNAP-Ed because these programs implement PSE efforts with local leaders in their communities. Results of this study suggest that Faithful Families provides comprehensive programming across the socioecological model in which, working together, these 2 national programs may effectively reach more individuals than traditional direct educationonly efforts (Table). Unlike traditional nutrition education programming, which can be offered within a short time frame, authentic engagement to carry out PSE changes with a community of faith can take months or even years to develop and build the trust necessary to make long-term changes. $^{10,11,13,15}$ It also takes clear delineation of the roles that SNAP-Ed professionals and EFNEP paraprofessionals have in implementing the programming. ${ }^{6}$ Faith communities are unlike many of the traditional settings within which health promotion programming takes place (eg, worksites or schools). It is important to consider the context of each individual faith community and plan for long-term commitment when working in communities of faith. ${ }^{10,11,13,15}$

Finally, this study found that faith communities might not be accustomed to participating in research or evaluation projects and are not always willing or able to carry out all aspects of program evaluation that a program necessitates. In other words, simply being a research study with necessary adherence to protocol was a barrier to participation. For example, the FCA was originally designed as a pre-post intervention tool to measure PSE changes at the beginning and end of a year of working with a faith community. However, as this study and others noted, it is difficult to receive followup data from faith communities because faith communities often have different rhythms and time frames that do not always adhere with grant schedules. ${ }^{13,15}$ Therefore, with more flexibility, other methods of PSE data collection, such as through success stories or annual program reports from local staff, may be a better way to track implementation of PSE changes.

\section{Limitations}

This study had limitations. First, the sample size was relatively small; only 
13 faith communities participated. Second, although the FCA was initially designed to be an audit tool that could measure PSE changes at the beginning and end of a year, facilitators in all 3 states found it difficult to collect a second FCA from faith community representatives. Although research demonstrated that supportive environments for healthy eating and physical activity can have long-term effects on health behaviors, ${ }^{5}$ this study did not evaluate the longer-term impacts of PSE changes implemented in the faith communities.

\section{IMPLICATIONS FOR RESEARCH AND PRACTICE}

The Faithful Families program implementation demonstrated successes in PSE outcomes and forged collaborations between EFNEP and SNAP-Ed. Programs such as Faithful Families can allow federally funded nutrition education programs to partner in ways that highlight each program's strengths. However, the study demonstrated that additional support regarding PSE measurement and evaluation is needed, particularly for the faith community settings, in which data collection and evaluation are not part of the community's norms and practices. Furthermore, this study revealed that careful recruitment and training of lay leaders is necessary. Because of their important role in program implementation, additional training materials and programs are needed to support this level of program engagement, including training for facilitators to help them work closely with a faith community to identify a lay leader and more rigorous training for lay leaders that helps them feel comfortable with the co-teaching role.

\section{ACKNOWLEDGMENTS}

The Southern RNECE-South was funded by the US Department of Agriculture, Food and Nutrition Service, and National Institute of Food and Agriculture.

\section{SUPPLEMENTARY DATA}

Supplementary data related to this article can be found at https://doi. org/10.1016/j.jneb.2019.11.011.

\section{REFERENCES}

1. Braveman PA, Cubbin C, Egerter S, Williams DR, Pamuk E. Socioeconomic disparities in health in the United States: what the patterns tell us. Am J Public Health. 2010;100(suppl 1): S186-S196.

2. Sudano JJ, Baker DW. Explaining US racial/ethnic disparities in health declines and mortality in late middle age: the roles of socioeconomic status, health behaviors, and health insurance. Soc Sci Med. 2006;62:909-922.

3. Auld G, Baker S, Conway L, Dollahite J, Lambea MC, McGirr K. Outcome effectiveness of the widely adopted EFNEP curriculum Eating Smart • Being Active. J Nutr Educ Behav. 2015;47:19-27.

4. Baral R, Davis GC, Blake S, You W, Serrano E. Using national data to estimate average cost effectiveness of EFNEP outcomes by state/territory. J Nutr Educ Behav. 2013;45:183-187.

5. Committee on Accelerating Progress in Obesity Prevention, Food and Nutrition Board, Institute of Medicine. Accelerating Progress in Obesity Prevention: Solving the Weight of the Nation. In: Glickman D, Parker L, Sim LJ, Del Valle Cook H, Miller EA, eds. Washington, DC: National Academies Press (US); 2012.

6. Medeiros LC, Butkus SN, Chipman H, Cox RH, Jones L, Little D. A logic model framework for community nutrition education. J Nutr Educ Behav. 2005;37:197-202.

7. Baruth M, Wilcox S. Multiple behavior change among church members taking part in the faith, activity, and nutrition program. J Nutr Educ Behav. 2013;45: 428-434.

8. Lancaster KJ, Carter-Edwards L, Grilo S, Shen C, Schoenthaler AM. Obesity interventions in African American faith-based organizations: a systematic review. Obes Rev Off J Int Assoc Study Obes. 2014;15(suppl 4):159-176.

9. Arriola KRJ, Hermstad A, Flemming SSC, et al. Promoting policy and environmental change in faith-based organizations: description and findings from a mini-grants program. Am J Health Promot. 2017;31:192-199.

10. Hardison-Moody A, Yao J. Faithful families, thriving communities: bridging faith and health through a statelevel partnership. Am J Public Health. 2019;109:363-368

11. Kaplan SA, Ruddock C, Golub M, et al. Stirring up the mud: using a community-based participatory approach to address health disparities through a faith-based initiative. J Health Care Poor Underserved. 2009;20:1111-1123.

12. Levin J. Faith-based initiatives in health promotion: history, challenges, and current partnerships. Am J Health Promot AJHP. 2014;28:139-141.

13. Campbell MK, Hudson MA, Resnicow K, Blakeney N, Paxton A, Baskin M. Church-based health promotion interventions: evidence and lessons learned. Annu Rev Public Health. 2007;28:213-234.

14. Worksite Health ScoreCard. Workplace Health Promotion. 2019. https:// www.cdc.gov/workplacehealthpromotion/initiatives/healthscorecard/index. html. Accessed November 6, 2019.

15. Cutts T, Gunderson G, Carter D, et al. From the Memphis model to the North Carolina way: lessons learned from emerging health system and faith community partnerships. $N \mathrm{C}$ Med J. 2017;78:267-272

16. Johnston JA, Konda K, Ablah E. Building capacity among laity: a faith-based health ministry initiative. J Relig Health. 2018;57:1276-1284.

17. Ammerman A, Corbie-Smith G, St George DMM, Washington C, Weathers B, Jackson-Christian B. Research expectations among African American church leaders in the PRAISE! project: a randomized trial guided by community-based participatory research. Am J Public Health. 2003;93:1720-1727.

18. Hardison-Moody A, Dunn C, Hall D, Jones L, Newkirk J, Thomas C. Multi-level partnerships support a comprehensive faith-based health promotion program. J Ext. 2011;49: 6IAW5.

19. Pullen-Smith B, Carter-Edwards L, Leathers KH. Community health ambassadors: a model for engaging community leaders to promote better health in North Carolina. J Public Health Manag Pract. 2008;14(suppl): S73-S81. 